\title{
Therapeutic Effects of Amino Acids in Liver Diseases: Current Studies and Future Perspectives
}

REVIEW

\author{
Da-Young Lee, Eun-Hee Kim \\ College of Pharmacy and Institute of Pharmaceutical Sciences, CHA University, Seongnam, Korea
}

\begin{abstract}
Hepatocellular carcinoma (HCC) is the most common primary malignant tumor of the liver and the third most common cause of cancer-related death worldwide. HCC is caused by infection of hepatitis B/C virus and liver dysfunctions, such as alcoholic liver disease, nonalcoholic fatty liver disease, and cirrhosis. Amino acids are organic substances containing amine and carboxylic acid functional groups. There are over 700 kinds of amino acids in nature, but only about 20 of them are used to synthesize proteins in cells. Liver is an important organ for protein synthesis, degradation and detoxification as well as amino acid metabolism. In the liver, there are abundant non-essential amino acids, such as alanine, aspartate, glutamate, glycine, and serine and essential amino acids, such as histidine and threonine. These amino acids are involved in various cellular metabolisms, the synthesis of lipids and nucleotides as well as detoxification reactions. Understanding the role of amino acids in the pathogenesis of liver and the effects of amino acid intake on liver disease can be a promising strategy for the prevention and treatment of liver disease. In this review, we describe the biochemical properties and functions of amino acids and to review how they have been applied to treatment of liver diseases.
\end{abstract}

(J Cancer Prev 2019;24:72-78)

Key Words: Amino acids, Liver diseases, Hepatic steatosis, Cirrhosis, Hepatocellular carcinoma

\section{INTRODUCTION}

Liver cancer is the second most common cancer among other cancers and is the leading cause of cancer deaths [1]. Hepatocellular carcinoma ( $\mathrm{HCC}$ ), which occurs approximately in $90 \%$ of primary liver cancer, causes serious health problems worldwide [2]. Liver cirrhosis is the main cause of HCC and almost one third of patients develop HCC. Hepatitis $C$ virus and hepatitis $B$ virus are also associated with HCC with cofactors, such as alcohol consumption, smoking and aflatoxin [3]. Hepatic steatosis is often accompanied by hepatocyte injury and inflammation leading to cirrhosis and HCC [4]. The main reason for the high mortality rate of HCC patients is the lack of effective treatment and the asymptomatic nature of early HCC [5,6].

Amino acids are organic substances containing amine and carboxylic acid functional groups [7], which are the basic unit for protein synthesis in cellular metabolism. Also, amino acids serve as intermediate metabolites affecting the biosynthesis of lipids, glutathione, nucleotides, glucosamine, and polyamines as well as cell proliferation and tricarboxylic acid circulating carbon $[8,9]$. Liver is an important organ for protein synthesis, degradation and detoxification as well as amino acid metabolism [10]. In the liver, abundant non-essential amino acids such as alanine, aspartate, glutamate, glycine, and serine and essential amino acids, such as histidine and threonine are present [9]. Recent studies have reported the role of amino acids as promising agents in the management of proliferative metabolism, and the application of amino acids has been rapidly increased in a variety of therapeutic fields [8]. Therefore, we described the biochemical properties and therapeutic functions of each amino acid for liver diseases in this review.

Received June 4, 2019, Revised June 18, 2019, Accepted June 19, 2019

Correspondence to: Eun-Hee Kim

E-mail: ehkim@cha.ac.kr, ORCID: Eun-Hee Kim, https://orcid.org/0000-0002-8523-0440

Copyright (C) 2019 Korean Society of Cancer Prevention

(c) This is an Open Access article distributed under the terms of the Creative Commons Attribution Non-Commercial License (http://creativecommons.org/icenses/by-nc/4.0) which permits unrestricted non-commercial use, distribution, and reproduction in any medium, provided the original work is properly cited. 


\section{FUNCTIONS OF AMINO ACIDS IN LIVER DISEASES}

\section{Alanine}

Alanine plays an important role in transferring ammonia from the periphery to the liver. Glucose is absorbed into the muscle and degraded by glycolysis to produce pyruvate then accepts amino group to form alanine. Produced alanine is released and uptaken into the liver and regenerates glucose and urea [11]. Alanine negatively regulates pyruvate kinase and participates in gluconeogenesis to help the production of glucose by hepatocytes in food shortages [12]. The alanine-pyruvate interconversion is caused by the alanine transaminase (ALT) enzyme expressed in the liver [13]. ALT is an enzyme that forms oxaloacetate, a liver metabolite [14]. ALT is abundant in the cytoplasm of hepatocytes and its activity in the liver is about 3,000 times higher than in serum. Therefore, when hepatocytes are damaged, ALT is released into the serum from injured hepatocytes, increasing the serum ALT activity [15]. Alanine treatment has been reported to significantly decrease the plasma levels of ALT and total bilirubin in Spragur-Dawley (SD) rat treated with D-galactosamine (D-gal) [16]. Alanine administration has been reported to prevent the elevation of ALT and histological liver damage in $\mathrm{CCl}_{4}$-induced hepatocyte necrosis rat model [17]. In addition, the treatment with alanine significantly decreased the level of lactate dehydrogenase in D-gal-treated rat hepatocytes [17]. In high-fat diet-induced obesity model, intake of alanine not only reduced body fat mass, but also decreased epididymal white adipose tissue. Moreover, the expressions of lipogenic genes such as fatty acid synthase (FAS) and liver-type fatty acid binding protein were significantly reduced by alanine treatment [18].

\section{Glutamate}

Glutamate inhibits T-cell and inflammatory responses and maintains the hepatic urea cycle in an active state for the detoxification of ammonia [7,12]. Glutamate modulates the transport of reductase across the membrane of mitochondria, thereby affecting glycolysis and cellular redox status [19]. Also, it acts as a major antioxidant in cells by controlling the homeostasis of free radicals [20]. Moreover, glutamate plays an important role in amino acid metabolism because it makes enzymes that metabolize and synthesize various amino acids in the liver [21]. In the rabbits treated with oxidized mustard oil, the intake of glutamate not only increased the level of glucose but also significantly decreased total levels of cholesterol and triglyceride in serum [22]. The oxidized mustard oil treatment significantly alters liver structure, increases fat accumulation, causes hepatitis, and necrosis. The co-administration of glutamate however, restored the function and structure of the liver [22]. In addition, it has been reported that the administration of alphaketoglutarate (AKG), a precursor of glutamate, reduced the activity of aspartate aminotransferase and ALT and improved the structure and physiological activity of the liver in lipopolysaccharide (LPS)-induced liver injury animal model [23]

\section{Aspartate}

Aspartate is an acidic amino acid considered as a non-essential amino acid [7]. However, many studies have shown that aspartate plays an important role in the physiological process of the liver $[24,25]$. Aspartate is required for the synthesis of purine, pyrimidine, asparagine, and arginine and is involved in the synthesis of inositol and beta-alanine [7]. It can be synthesized from oxaloacetate, which plays an important role in the citric acid cycle and affects cellular redox status [19]. Supplementation of aspartate has been reported to suppress atherosclerosis and fatty liver disease in cholesterol-fed rabbits [26]. It has been reported that intake of aspartate can inhibit the development of hepatic steatosis and liver fibrosis [26]. The treatment with aspartate has also shown to have beneficial effects in attenuating liver damage through down-regulation of the expression of pro-inflammatory mediators, such as toll-like receptor 4 and nucleotide-binding oligomerization domain protein signaling genes in LPS-induced liver injury models [27].

\section{Glycine}

Glycine is essential raw material for the synthesis of DNAs and RNAs. It can also improve the immune response and also involved in the absorption of calcium [28]. Glycine has been reported to protect against hypoxia in kidney proximal tubules and hepatocyte [29,30]. In addition, glycine activates chloride channels in Kupffer cells and hyperpolarizes the membrane of cells. It increases intracellular calcium ion concentration and also reduces the levels of superoxide ions via glycine gated chloride channels [31]. In chronic rat hepatotoxicity models induced by $\mathrm{CCl}_{4}$, glycine treatment has been reported to prevent liver fibrosis by inhibiting the activation of Kupffer cells and preventing the release of pro-inflammatory and pro-fibrogenic cytokines [32]. Glycine has been also reported to increase the levels of myeloperoxidase and decrease the levels of TNF- $\alpha$, thereby maintaining cell viability and organ regeneration capacity after liver transplantation in liver transplantation rat models [33]. Administration of glycine decreased oxidative stress and increased the expression of 
antioxidant enzymes, such as glutathione peroxidase, superoxide dismutase, and catalase in ethanol-induced liver injury model [34]. In addition, glycine administration not only increased the serum levels of vitamin $\mathrm{E}$ and $\mathrm{C}$, but also relieved the infiltration of inflammatory cells in liver [34]. It has also been reported that ingestion of glycine improves survival rate and liver function by controlling the production of pro-inflammatory or anti-inflammatory cytokines in the endotoxin-induced liver injury mouse model [35]. Similarly, dietary supplementation of glycine has been shown to alleviate liver and lung injury and improve survival rate in SD rats injected with endotoxin intravenously [36]. In addition, dietary glycine accelerated the recovery of alcohol-induced liver damage over 4 weeks [37].

\section{Histidine}

Histidine regulates gene expression and biological activity of proteins through methylation. It also regulates the structure and function of hemoglobin [7]. It has been reported that histidine ingestion reduces the accumulation of copper in the liver and promotes the excretion of copper into the urine in Wilson's disease which is caused by accumulation of copper [38]. The concentration of histidine, hepatic antioxidant enzyme activity, the levels of lipids and ALT were analyzed in long-evans cinnamon rats. As a result, the levels of cholesterol and ALT were reduced in rats under histidine diet [38]. Moreover, preliminary intake of histidine in a BALB/CA mouse model with hepatic injury induced by acetaminophen has been reported to reduce the levels of inflammatory cytokines, interleukin (IL)-6, IL-10, and TNF- $\alpha$ in the liver [39]. It has also been reported that the treatment with histidine alleviates hyperglycemia, hyperlipidemia, oxidation, and inflammation in diabetic mouse [39,40]. Histidine has been reported to regulate hepatic glucose metabolism and activate hepatic STAT3 to act as an agent for the treatment of type 2 diabetes [41]. Histidine ingestion decreased lipogenesis and cholesterol metabolism related to mRNA expression, such as FAS, HMG-CoA reductase, regulatory element-binding protein-1c, and regulatory element-binding protein-2, which reduced body weight, epididymal fat and the levels of hepatic triglyceride and cholesterol [42]. It has also been reported that insulin sensitivity is improved and hyper-insulinemia is alleviated by the treatment with histidine [42].

\section{Serine}

Serine is classified as a non-essential amino acid because serine can be produced from food consumption, degradation of proteins, glycine, saccharide metabolite and phospholipids
[43,44]. Serine, like glycine, provides precursors of proteins, nucleic acids, and lipids [45]. Moreover, serine which is involved in glycogen storage in liver and muscle, forms antibodies to enhance immunity, and helps the formation of the myelin sheath in nerve fibers [28]. Analysis of transcriptomic data of non-alcoholic steatohepatitis (NASH) patients in clinical trials confirmed the changes in several gene expressions by serine administration [43]. The hydroxymethyltransferases, cystein synthesis and aminoacyl-tRNA biosynthesis genes were decreased, whereas sphingosine synthesis genes were increased. It has been reported that the elevation of serine levels in hepatocytes via serine ingestion may have a beneficial effect on NASH patients through the regulation of these genes [43]. In alcohol-induced fatty liver mouse model, serine intake has been reported to reduce the hepatic level of triglyceride and neutral lipid accumulation [46]. It was also reported that serine increases the levels of glutathione and S-adenosylmethionine (SAMe), respectively [46]

\section{Threonine}

Threonine is an essential amino acid and involved in many physiological and biochemical processes including growth, absorption, digestion and immune function [47-50]. In order to maintain intestinal function, threonine modulates the synthesis and immunity of the mucin proteins [51]. Also, threonine affects the synthesis of glycine and protein phosphorylation [7]. Threonine catabolism occurs mainly in the liver through two pathways [52], the enzymes threonine dehydratase (TDH) and threonine dehydrogenase (TDG). The enzyme, TDH, acts as a cytoplasmic enzyme to produce 2-ketobutyric acid and $\mathrm{NH}_{4}{ }^{+}$ [53.54]. The enzyme TDG is a mitochondrial enzyme that produces glycine and aminoacetone [55]. In rat with hepatitis, the activity of TDH and TDG were markedly decreased. Therefore, the concentration of threonine in the liver was increased [56]. Dietary intake of threonine deficiency has been reported to reduce energy expenditure and promote mitochondrial uncoupling in the liver [57].

\section{Others}

Methionine is an essential amino acid in humans. Methionine converts to SAMe and changes the methyl group of SAMe to S-adenosylhomocysteine [58]. The SAMe has isoenzymes, such as MAT1A and MAT2A. MAT1A is expressed primarily in the human liver and MAT2A is expressed in all organs including liver [59]. The patients with liver cirrhosis have abnormal methionine metabolism [60] and decreased MAT1A expression [61]. Indeed, 
several studies have shown that mice treated with methionine and choline deficient diets develop more severe steatohepatitis and HCC [62]. Leucine is an essential amino acid and is required for protein biosynthesis. Most leucine is metabolized in the liver, adipose tissue and muscle. Recent studies have shown that ingestion of leucine reverses abnormal metabolisms, improves glucose tolerance and decreases hepatic steatosis and inflammation in adipose tissue [63]. Arginine is necessary for cell division, removal of ammonia in the body and protein biosynthesis. Administration of arginine not only reduced endotoxin and lipid peroxidation induced by alcohol in liver injury rat model, but also reduced the level of inflammation factors, such as NF-kB, TNF- $\alpha$, and COX2 [64].

\section{CONCLUSION}

Liver cancer mortality is still high in the world because of its asymptomatic, difficulty in diagnosis and lack of effective treatment. Failure to treat the liver damaged by external factors can lead to more severe conditions such as fibrosis, cirrhosis and liver cancer (Fig. 1) [65]. The liver is known to be involved in metabolic homeostasis, especially in glucose homeostasis through the alanine-glucose cycle [66]. The alanine-glucose cycle is a mutual reaction between the muscle and the liver. When the muscle protein breaks down the amino acids due to energy needs, released nitrogen participates in conversion of glutamate and pyruvate to AKG and alanine through transamination. The produced alanine is a metabolic pathway to the liver where pyruvate is used to make glucose $[67,68]$. Amino acids have been found to be involved in a variety of biological activities, and the proper treatment with amino acids in liver disease can have positive effects summarized in Table 1 . Recent studies reported the application of multiple amino acids such as peptides and branched chain amino acids (BCAAs) have beneficial effects in various liver diseases [69]. Peptides, molecules of a combination of amino acids linked by peptide bonds, have been studied as promising therapeutics in the treatment of cancer diseases $[70,71]$. In additional studies, BCAA composed of leucine, isoleucine and valine had the inhibitory effect on the proliferation of liver cancer cells $[72,73]$. However, the excessive amounts of amino acids have been reported to cause several problems. Excessive dietary intake of histidine resulted in hyperlipidemia, hepercholesterolemia and hepatic enlargement in animals [74,75] and excessive intake of tryptophan resulted in fast weight loss in rats [76]. Increased circulating BCAA has been associated with non-alcoholic fatty liver disease and hepatic injury [77]. These

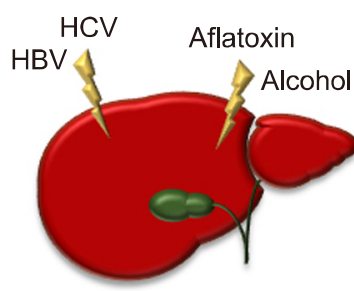

Healthy liver

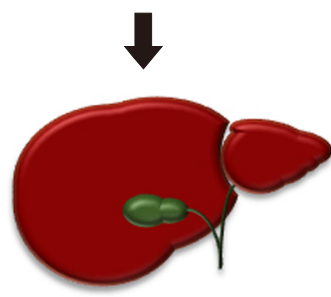

Liver

inflammation

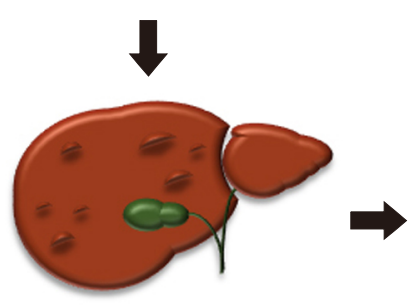

Liver fibrosis

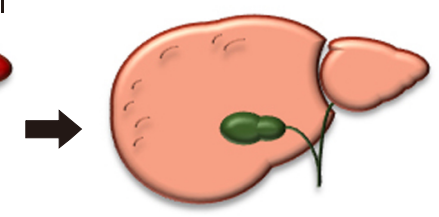

Fatty liver

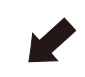

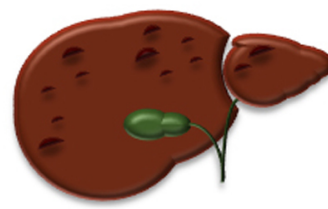

Cirrhosis
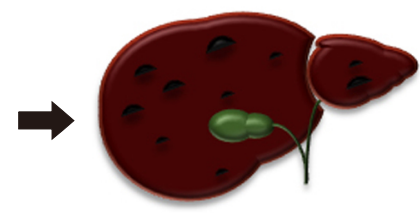

Liver cancer
Figure 1. The spectrum of liver disease. A healthy liver can perform normal functions effectively. The liver can be damaged by viruses, toxins and alcohol. Fat accumulation by obesity or other factors causes fatty liver. Inflammation induced by liver injury can cause scar tissue and fibrosis. Leaving fibrosis untreated, the flow of blood through the liver is blocked and the liver function may deteriorate, which is called cirrhosis. Continuous liver disease can lead to liver cancer. HBV, hepatitis B virus; HCV, hepatitis $C$ virus. 
Table 1. Effects of amino acids on several liver diseases

\begin{tabular}{|c|c|c|c|c|c|}
\hline Amino acid & Model & Subsection & Disease & Treatment & Ref No. \\
\hline \multirow[t]{4}{*}{ Alanine } & In vitro & Rat hepatocyte & Treated with D-gal & $60 \mathrm{mM}$ & [17] \\
\hline & In vivo & SD rat & D-gal-induced hepatocyte necrosis & Aqueous alanine solution & \\
\hline & & Wistar rat & $\mathrm{CCl}_{4}$-induced hepatocyte necrosis & $2 \mathrm{~g} / \mathrm{kg}$ intraperitoneal injection & \\
\hline & & C57BL/6 mouse & High-fat diet-induced obesity & Diet & {$[18]$} \\
\hline \multirow[t]{2}{*}{ Glutamate } & In vivo & Rabbit & Mustard seed oil-induced oxidation & $1,2,3 \mathrm{~g} / \mathrm{kg}$ diet & [22] \\
\hline & & Piglet & LPS-induced hepatic injury & $1 \%$ AKG diet & [23] \\
\hline \multirow[t]{2}{*}{ Aspartate } & In vivo & Rabbit & Cholesterol-fed induced fatty liver disease & $12.5 \mathrm{mM}$ aspartate in water & [26] \\
\hline & & Weaning piglet & LPS-induced liver injury & $0.5,1 \%$ diet & [27] \\
\hline \multirow[t]{6}{*}{ Glycine } & In vivo & Wistar/Han rat & $\mathrm{CCl}_{4}$-induced hepatic fibrosis & $5 \%$ diet & [32] \\
\hline & & Lewis rat & Liver transplantation & $300 \mathrm{mM}$ intravenous injection & [33] \\
\hline & & Wistar rat & Alcohol-induced liver injury & $0.6 \mathrm{~g} / \mathrm{kg}$ & [34] \\
\hline & & $\mathrm{BALB} / \mathrm{c}$ mouse & LPS-induced liver damage & $5 \%$ diet & [36] \\
\hline & & $\mathrm{SD}$ rat & Intravenous injection of endotoxin & $5 \%$ diet & [37] \\
\hline & & Wistar rat & Alcohol-induced liver injury & $2 \%$ diet & [38] \\
\hline \multirow[t]{5}{*}{ Histidine } & In vivo & LEC rat & Excess copper accumulation-induced hepatitis & Excess-histidine diet & [39] \\
\hline & & $\mathrm{BALB} / \mathrm{CA}$ mouse & Acetaminophen-induced liver injury & $0.5,1,2 \mathrm{~g} / \mathrm{L}$ in water & [40] \\
\hline & & $\mathrm{BALB} / \mathrm{cA}$ mouse & Streptozotocin-induced diabetes & $0.5,1 \mathrm{~g} / \mathrm{L}$ in water & [41] \\
\hline & & C57BL/6J mouse & Histamine $\mathrm{H}_{1}$ receptor knockout & $\begin{array}{l}\text { Intravenous and } \\
\text { intracerebroventricular } \\
\text { administration }\end{array}$ & [42] \\
\hline & & C57BL/6 mouse & Hepatic steatosis-induced high saturated fat diet & $1 \mathrm{~g} / \mathrm{L}$ in water & [43] \\
\hline \multirow[t]{2}{*}{ Serine } & In vivo & C57BL/6 mouse & Alcohol-induced fatty liver & $20,200 \mathrm{mg} / \mathrm{kg}$ diet & [47] \\
\hline & Clinical & Human & Non-alcoholic fatty liver disease patients & & \\
\hline
\end{tabular}

SD, Spragur-Dawley; D-gal, D-galactosamine; LPS, lipopolysaccharide; AKG, alpha-ketoglutarate.

results demonstrated that high protein or amino acids consumption may generate further dangerous metabolic disorders and liver injury. Therefore, the application of amino acids for the patients with liver diseases should be performed carefully. In conclusion, the treatment of amino acids in patients with liver diseases may be a promising treatment, but further studies are still needed for the proper amino acid intake and application in various liver diseases.

\section{ACKNOWLEDGMENTS}

This work was supported by Korea Institute of Planning and Evaluation for Technology in Food, Agriculture, Forestry and Fisheries (IPET) through Agri-Bio industry Technology Development Program, funded by Ministry of Agriculture, Food and Rural Affairs (MAFRA) (317004-4).

\section{CONFLICTS OF INTEREST}

No potential conflicts of interest were disclosed.

\section{REFERENCES}

1. Singh KP, Jayasomu RS. Bombyx mori: a review of its potential as a medicinal insect. Pharm Biol 2008:40:28-32.

2. Llovet JM, Villanueva A, Lachenmayer A, Finn RS. Advances in targeted therapies for hepatocellular carcinoma in the genomic era. Nat Rev Clin Oncol 2015;12:408-24.

3. Llovet JM, Zucman-Rossi J, Pikarsky E, Sangro B, Schwartz M, Sherman M, et al. Hepatocellular carcinoma. Nat Rev Dis Primers 2016;2:16018

4. Berlanga A, Guiu-Jurado E, Porras JA, Auguet T. Molecular pathways in non-alcoholic fatty liver disease. Clin Exp Gastroenterol 2014;7:221-39.

5. Whittaker S, Marais R, Zhu AX. The role of signaling pathways in the development and treatment of hepatocellular carcinoma. Oncogene 2010:29:4989-5005.

6. Thomas MB, Abbruzzese JL. Opportunities for targeted therapies in hepatocellular carcinoma. J Clin Oncol 2005;23:8093-108.

7. Wu G. Amino acids: metabolism, functions, and nutrition. Amino Acids 2009:37:1-17.

8. Tsun ZY, Possemato R. Amino acid management in cancer. Semin Cell Dev Biol 2015:43:22-32.

9. Lukey MJ, Katt WP, Cerione RA. Targeting amino acid metabolism for cancer therapy. Drug Discov Today 2017;22:796-804.

10. Dejong CH, van de Poll MC, Soeters PB, Jalan R, Olde Damink SW. Aromatic amino acid metabolism during liver failure. J Nutr 2007;137:1579S-85S; discussion 1597S-8S.

11. Felig P, Pozefsky T, Marliss E, Cahill GF Jr. Alanine: key role in gluconeogenesis. Science 1970;167:1003-4. 
12. Meijer AJ. Amino acids as regulators and components of nonproteinogenic pathways. J Nutr 2003;133:2057S-62S.

13. McCommis KS, Chen Z, Fu X, McDonald WG, Colca JR, Kletzien $\mathrm{RF}$, et al. Loss of mitochondrial pyruvate carrier 2 in the liver leads to defects in gluconeogenesis and compensation via pyruvate-alanine cycling. Cell Metab 2015:22:682-94.

14. Wolf PL. Biochemical diagnosis of liver disease. Indian J Clin Biochem 1999;14:59-90.

15. Kim WR, Flamm SL, Di Bisceglie AM, Bodenheimer HC. Serum activity of alanine aminotransferase (ALT) as an indicator of health and disease. Hepatology 2008:47:1363-70.

16. Maezono K, Mawatari K, Kajiwara K, Shinkai A, Maki T. Effect of alanine on D-galactosamine-induced acute liver failure in rats. Hepatology 1996;24:1211-6.

17. Maezono K, Kajiwara K, Mawatari K, Shinkai A, Torii K, Maki T. Alanine protects liver from injury caused by F-galactosamine and CCl4. Hepatology 1996;24:185-91.

18. Freudenberg A, Petzke KJ, Klaus S. Dietary L-leucine and L-alanine supplementation have similar acute effects in the prevention of high-fat diet-induced obesity. Amino Acids 2013;44: 519-28.

19. Brosnan JT. Amino acids, then and now: a reflection on Sir Hans Krebs' contribution to nitrogen metabolism. IUBMB Life 2001;52: 265-70.

20. Wu G, Fang YZ, Yang S, Lupton JR, Turner ND. Glutathione metabolism and its implications for health. J Nutr 2004:134:489-92.

21. Brosnan ME, Brosnan JT. Hepatic glutamate metabolism: a tale of 2 hepatocytes. Am J Clin Nutr 2009:90:857S-61S.

22. Zeb A, Rahman SU. Protective effects of dietary glycine and glutamic acid toward the toxic effects of oxidized mustard oil in rabbits. Food Funct 2017;8:429-36.

23. Wang L, Hou Y, Yi D, Li Y, Ding B, Zhu H, et al. Dietary supplementation with glutamate precursor $\alpha$-ketoglutarate attenuates lipopolysaccharide-induced liver injury in young pigs. Amino Acids 2015:47:1309-18.

24. Wu G. Functional amino acids in nutrition and health. Amino Acids 2013:45:407-11.

25. Wu G, Wu Z, Dai Z, Yang Y, Wang W, Liu C, et al. Dietary requirements of "nutritionally non-essential amino acids" by animals and humans. Amino Acids 2013;44:1107-13.

26. Yanni AE, Agrogiannis G, Nomikos T, Fragopoulou E, Pantopoulou A, Antonopoulou S, et al. Oral supplementation with L-aspartate and L-glutamate inhibits atherogenesis and fatty liver disease in cholesterol-fed rabbit. Amino Acids 2010;38:1323-31.

27. Leng W, Liu Y, Shi H, Li S, Zhu H, Pi D, et al. Aspartate alleviates liver injury and regulates mRNA expressions of TLR4 and NOD signaling-related genes in weaned pigs after lipopolysaccharide challenge. J Nutr Biochem 2014:25:592-9.

28. Ji SD, Kim NS, Kweon HY, Choi BH, Yoon SM, Kim KY, et al. Nutrient compositions of Bombyx mori mature silkworm larval powders suggest their possible health improvement effects in humans. J Asia-Pac Entomol 2016;19:1027-33.

29. Weinberg JM, Davis JA, Abarzua M, Rajan T. Cytoprotective effects of glycine and glutathione against hypoxic injury to renal tubules. J Clin Invest 1987;80:1446-54.

30. Marsh DC, Vreugdenhil PK, Mack VE, Belzer FO, Southard JH. Glycine protects hepatocytes from injury caused by anoxia, cold ischemia and mitochondrial inhibitors, but not injury caused by calcium ionophores or oxidative stress. Hepatology 1993;17:91-8.
31. Wheeler M, Stachlewitz RF, Yamashina S, Ikejima K, Morrow AL, Thurman RG. Glycine-gated chloride channels in neutrophils attenuate calcium influx and superoxide production. FASEB J 2000;14:476-84.

32. Rivera CA, Bradford BU, Hunt KJ, Adachi Y, Schrum LW, Koop DR, et al. Attenuation of $\mathrm{CCl}(4)$-induced hepatic fibrosis by $\mathrm{GdCl}(3)$ treatment or dietary glycine. Am J Physiol Gastrointest Liver Physiol 2001;281:G200-7.

33. Rentsch M, Puellmann K, Sirek S, Iesalnieks I, Kienle K, Mueller $\mathrm{T}$, et al. Benefit of Kupffer cell modulation with glycine versus Kupffer cell depletion after liver transplantation in the rat: effects on postischemic reperfusion injury, apoptotic cell death graft regeneration and survival. Transpl Int 2005;18:1079-89.

34. Senthilkumar R, Viswanathan P, Nalini N. Effect of glycine on oxidative stress in rats with alcohol induced liver injury. Pharmazie 2004:59:55-60.

35. Xu FL, You HB, Li XH, Chen XF, Liu ZJ, Gong JP. Glycine attenuates endotoxin-induced liver injury by downregulating TLR4 signaling in Kupffer cells. Am J Surg 2008;196:139-48.

36. Ikejima K, Iimuro Y, Forman DT, Thurman RG. A diet containing glycine improves survival in endotoxin shock in the rat. Am J Physiol 1996;271:G97-103.

37. Yin M, Ikejima K, Arteel GE, Seabra V, Bradford BU, Kono H, et al. Glycine accelerates recovery from alcohol-induced liver injury. J Pharmacol Exp Ther 1998;286:1014-9.

38. Xu H, Sakakibara S, Morifuji M, Salamatulla Q, Aoyama Y. Excess dietary histidine decreases the liver copper level and serum alanine aminotransferase activity in Long-Evans Cinnamon rats. $\mathrm{Br} \mathrm{J}$ Nutr 2003:90:573-9.

39. Yan SL, Wu ST, Yin MC, Chen HT, Chen HC. Protective effects from carnosine and histidine on acetaminophen-induced liver injury. J Food Sci 2009;74:H259-65.

40. Lee YT, Hsu CC, Lin MH, Liu KS, Yin MC. Histidine and carnosine delay diabetic deterioration in mice and protect human low density lipoprotein against oxidation and glycation. Eur J Pharmacol 2005:513:145-50.

41. Kimura K, Nakamura Y, Inaba Y, Matsumoto M, Kido Y, Asahara S, et al. Histidine augments the suppression of hepatic glucose production by central insulin action. Diabetes 2013;62:2266-77.

42. Mong MC, Chao CY, Yin MC. Histidine and carnosine alleviated hepatic steatosis in mice consumed high saturated fat diet. Eur J Pharmacol 2011;653:82-8.

43. Mardinoglu A, Agren R, Kampf C, Asplund A, Uhlen M, Nielsen J. Genome-scale metabolic modelling of hepatocytes reveals serine deficiency in patients with non-alcoholic fatty liver disease. Nat Commun 2014:5:3083.

44. de Koning TJ, Snell K, Duran M, Berger R, Poll-The BT, Surtees R. L-serine in disease and development. Biochem J 2003;371(Pt 3):653-61

45. Amelio I, Cutruzzolá F, Antonov A, Agostini M, Melino G. Serine and glycine metabolism in cancer. Trends Biochem Sci 2014; 39:191-8

46. Sim WC, Yin HQ, Choi HS, Choi YJ, Kwak HC, Kim SK, et al. L-serine supplementation attenuates alcoholic fatty liver by enhancing homocysteine metabolism in mice and rats. J Nutr 2015; 145:260-7.

47. Feng L, Peng Y, Wu P, Hu K, Jiang WD, Liu Y, et al. Threonine affects intestinal function, protein synthesis and gene expression of TOR in Jian carp (Cyprinus carpio var. Jian). PLoS One 2013;8: 
e69974.

48. Yun H, Park G, Ok I, Katya K, Hung S, Bai SC. Evaluation of optimum dietary threonine requirement by plasma free threonine and ammonia concentrations in surgically modified rainbow trout, Oncorhynchus mykiss. Asian-Australas J Anim Sci 2015;28: 551-8.

49. Habte-Tsion HM, Ge X, Liu B, Xie J, Ren M, Zhou Q, et al. A deficiency or an excess of dietary threonine level affects weight gain, enzyme activity, immune response and immune-related gene expression in juvenile blunt snout bream (Megalobrama amblycephala). Fish Shellfish Immunol 2015;42:439-46.

50. Habte-Tsion HM, Ren M, Liu B, Xie J, Ge X, Chen R, et al. Threonine affects digestion capacity and hepatopancreatic gene expression of juvenile blunt snout bream (Megalobrama amblycephala). Br J Nutr 2015;114:533-43.

51. Faure M, Choné F, Mettraux C, Godin JP, Béchereau F, Vuichoud J, et al. Threonine utilization for synthesis of acute phase proteins, intestinal proteins, and mucins is increased during sepsis in rats. J Nutr 2007; 137:1802-7.

52. Bird MI, Nunn PB. Metabolic homoeostasis of L-threonine in the normally-fed rat. Importance of liver threonine dehydrogenase activity. Biochem J 1983;214:687-94.

53. Kang-Lee YA, Harper AE. Threonine metabolism in vivo: effect of threonine intake and prior induction of threonine dehydratase in rats. J Nutr 1978;108:163-75.

54. Inoue $\mathrm{H}$, Pitot $\mathrm{HC}$. Regulation of the synthesis of serine dehydratase isozymes. Adv Enzyme Regul 1970;8:289-96.

55. Ishikawa $\mathrm{K}$, Higashi N, Nakamura T, Matsuura T, Nakagawa A. The first crystal structure of L-threonine dehydrogenase. J Mol Biol 2007;366:857-67.

56. Ma XL, Baraona E, Hernández-Muñoz R, Lieber CS. High levels of acetaldehyde in nonalcoholic liver injury after threonine or ethanol administration. Hepatology 1989:10:933-40.

57. Ross-Inta CM, Zhang YF, Almendares A, Giulivi C. Threonine-deficient diets induced changes in hepatic bioenergetics. Am J Physiol Gastrointest Liver Physiol 2009;296:G1130-9.

58. Mato JM, Martínez-Chantar ML, Lu SC. Methionine metabolism and liver disease. Annu Rev Nutr 2008;28:273-93.

59. Kotb M, Mudd SH, Mato JM, Geller AM, Kredich NM, Chou JY, et al. Consensus nomenclature for the mammalian methionine adenosyltransferase genes and gene products. Trends Genet 1997; 13:51-2.

60. Horowitz JH, Rypins EB, Henderson JM, Heymsfield SB, Moffitt $\mathrm{SD}$, Bain RP, et al. Evidence for impairment of transsulfuration pathway in cirrhosis. Gastroenterology 1981;81:668-75.

61. Avila MA, Berasain C, Torres L, Martín-Duce A, Corrales FJ, Yang $\mathrm{H}$, et al. Reduced mRNA abundance of the main enzymes involved in methionine metabolism in human liver cirrhosis and hepatocellular carcinoma. J Hepatol 2000;33:907-14.

62. Lu SC, Alvarez L, Huang ZZ, Chen L, An W, Corrales FJ, et al.
Methionine adenosyltransferase $1 \mathrm{~A}$ knockout mice are predisposed to liver injury and exhibit increased expression of genes involved in proliferation. Proc Natl Acad Sci U S A 2001;98:5560-5.

63. Macotela Y, Emanuelli B, Bång AM, Espinoza DO, Boucher J, Beebe K, et al. Dietary leucine: an environmental modifier of insulin resistance acting on multiple levels of metabolism. PLoS One 2011;6:e21187.

64. Nanji AA, Jokelainen K, Lau GK, Rahemtulla A, Tipoe GL, Polavarapu R, et al. Arginine reverses ethanol-induced inflammatory and fibrotic changes in liver despite continued ethanol administration. J Pharmacol Exp Ther 2001;299:832-9.

65. Dowman JK, Tomlinson JW, Newsome PN. Pathogenesis of non-alcoholic fatty liver disease. QJM 2010;103:71-83.

66. van den Berghe $\mathrm{G}$. The role of the liver in metabolic homeostasis: implications for inborn errors of metabolism. J Inherit Metab Dis 1991;14:407-20.

67. Karmen A, Wroblewski F, Ladue JS. Transaminase activity in human blood. J Clin Invest 1955;34:126-31.

68. Oosterveer MH, Schoonjans K. Hepatic glucose sensing and integrative pathways in the liver. Cell Mol Life Sci 2014;71:1453-67.

69. Park JG, Tak WY, Park SY, Kweon YO, Jang SY, Lee YR, et al. Effects of branched-chain amino acids (BCAAs) on the progression of advanced liver disease: a Korean nationwide, multicenter, retrospective, observational, cohort study. Medicine (Baltimore) 2017; 96:e6580.

70. Thundimadathil J. Cancer treatment using peptides: current therapies and future prospects. J Amino Acids 2012;2012:967347.

71. Xiao YF, Jie MM, Li BS, Hu CJ, Xie R, Tang B, et al. Peptide-based treatment: a promising cancer therapy. J Immunol Res 2015; 2015:761820.

72. Sugiyama K, Yu L, Nagasue N. Direct effect of branched-chain amino acids on the growth and metabolism of cultured human hepatocellular carcinoma cells. Nutr Cancer 1998;31:62-8.

73. Ninomiya S, Shimizu M, Imai $\mathrm{K}$, Takai $\mathrm{K}$, Shiraki M, Hara T, et al. Possible role of visfatin in hepatoma progression and the effects of branched-chain amino acids on visfatin-induced proliferation in human hepatoma cells. Cancer Prev Res (Phila) 2011:4: 2092-100.

74. Kerr GR, Wolf RC, Waisman HA. Hyperlipemia in infant monkeys fed excess L-histidine. Proc Soc Exp Biol Med 1965;119:561-2.

75. Solomon JK, Geison RL. Effect of excess dietary L-histidine on plasma cholesterol levels in weanling rats. J Nutr 1978;108: 936-43.

76. Funk DN, Worthington-Roberts B, Fantel A. Impact of supplemental lysine or tryptophan on pregnancy course and outcome in rats. Nutr Res 1991;11:501-12.

77. Zhang F, Zhao S, Yan W, Xia Y, Chen X, Wang W, et al. Branched chain amino acids cause liver injury in obese/diabetic mice by promoting adipocyte lipolysis and inhibiting hepatic autophagy. EBioMedicine 2016;13:157-67. 